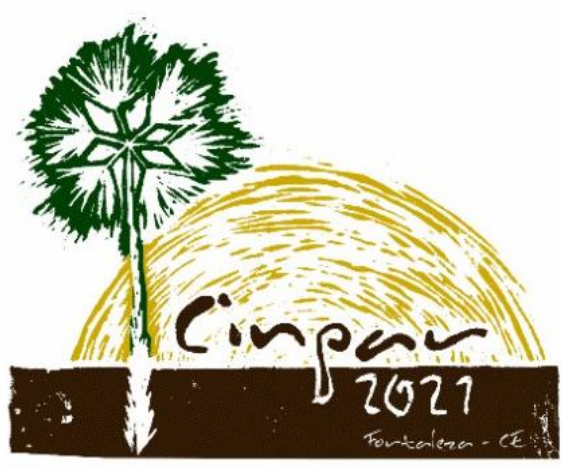

XVII Congresso Internacional sobre Patologia e

Reabilitação das Construções

XVII Congreso Internacional sobre Patología y Rehabilitación de las Construcciones

XVII International Conference on Pathology and Constructions Rehabilitation

FORTALEZA (Brasil), 3 a 5 de junho de 2021

https://doi.org/10.4322/CINPAR.2021.153

\title{
Análise do efeito da adição de aditivo cristalizante na autocicatrização do concreto
}

\section{Analysis of the effect of the addition of crystallizing additive on self-healing of concrete}

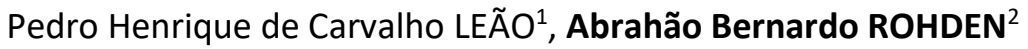 \\ ${ }^{1}$ Fundação Universidade Regional de Blumenau, Blumenau, Brasil, pedro01leao@hotmail.com \\ ${ }^{2}$ Fundação Universidade Regional de Blumenau, Blumenau, Brasil, abrcivil@gmail.com
}

\begin{abstract}
Resumo: A durabilidade das estruturas de concreto armado está intrincicamente ligada à formação de fissuras. As fissuras são minúsculas trincas que podem ter decorrências de pequenas variações de deformabilidade, retração do concreto, dosagem incorreta dos materiais, baixa resistência à tração e outros fatores que podem estar diretamente ligados à composição dos materiais e variabilidade temporal. Dentre as consequências do seu aparecimento está a redução da resistência à flexão do elemento estrutural. Para tanto, a abertura de uma fissura facilita a passagem de fluidos para a parte interna do concreto, expondo a estrutura à reações quimícas, que causam a deterioração dos seus componentes, como a corrosão das armaduras, por exemplo. Toda estrutura durante sua vida útil terá eventuais surgimentos de fissuras e isso não é incomum. Com base nisto, este trabalho teve como objetivo principal de avaliar a influência do aditivo cristalizante na autocicatrização do concreto. Para fins de atingimento deste objetivo, foram moldados 20 corpos de prova utilizando um traço base e outros 20 do mesmo traço contendo o aditivo cristalizante. Além disso, foram concretadas duas lajes, uma contendo e outra não o aditivo cristalizante em seu traço. Os corpos de prova e as lajes foram submetidos à ensaios de resistência à compressão e de penetração de água sob pressão, para fins de comprovação de possíveis melhorias na resistência à compressão e na capacidade impermeabilizante do concreto, respectivamente. É possível afirmar a cerca dos resultados obtidos no ensaio de penetração de água sob pressão é que respeitando o valor máximo de abertura característica de fissuras, igual a 0,4 mm, definido pela NBR 6118 (ABNT, 2014), a quantidade de água percolada em ambas as lajes não foi suficiente para se caracterizar o gotejamento, que, em uma situação real, poderia ocasionar em danos para uma edificação.
\end{abstract}

Palavras-chave: concreto armado; fissuras. autocicatrização. durabilidade.

\section{Introdução}

Takagi (2013) realizou estudos sobre possíveis melhorias na colmatação natural do concreto, ou seja, da capacidade do concreto de reparar suas próprias fissuras, através da incorporação de aditivo cristalizante ao seu traço. Em seu experimento, Takagi (2013) utilizou como mecanismo de gatilho a formação fissuras em amostras de concreto e a exposição das amostras à água, que, neste processo, após a penetração permitida pela fissura, tinha a função de ativar o catalisador cristalino. O catalisador, supostamente, elevaria a alcalinidade da água dentro das fissuras, favorecendo a formação de produtos hidratados estáveis nas faces internas das fissuras estáticas de até $0,4 \mathrm{~mm}$ de espessura.

Takagi (2013) realizou ensaios de penetração de água sob pressão conforme a NBR 10787 (ABNT, 2011), utilizando corpos de prova prismáticos de $250 \times 250 \times 125 \mathrm{~mm}$, após 28 dias (1 CP × 6 traços) e 56 dias de idade (2 CPs x 6 traços). Após a análise dos resultados, Takagi (2013) pôde confirmar uma diminuição na 
penetração de água nos corpos de prova que apresentavam o aditivo cristalizante em seu traço, comprovando, ao menos, uma melhoria na capacidade impermeabilizante do concreto.

Bianchin (2018) realizou um estudo que consistiu em uma análise em concretos fissurados nas primeiras idades, para avaliar o fenômeno da autocicatrização da matriz cimentícia. Suas análises tinham como objetivo comparar o fechamento das fissuras ao longo do tempo em concretos produzidos com materiais usuais (cimento, brita e areia) e concretos com aditivo impermeabilizante por cristalização.

De forma semelhante ao trabalho realizado por Takagi (2013), Bianchin (2018) moldou diversos corpos de provas, alterando o consumo de cimento, a relação água/cimento e a presença ou não de aditivo cristalizante em seus traços. Aos 7 dias de idade, os corpos de prova foram submetidos à um carregamento de compressão de valor igual a $85 \%$ da sua carga de ruptura.

Posteriormente, Bianchin (2018) realizou ensaios de resistência à compressão e de penetração de íons de cloreto, visando avaliar a durabilidade do concreto, e pôde constatar que, nos corpos de prova com relação água/cimento de 0,43 , houve uma melhoria na resistência à compressão. Na questão da durabilidade, Bianchin (2018) notou que o aditivo cristalizante não influenciou na autocicatrização das fissuras, pois a penetração de íons de cloreto não foi impedida nos corpos de prova fissurados.

Moreira (2016) desenvolveu um estudo que buscou determinar a influência de um aditivo redutor de permeabilidade (ARP) na capacidade impermeabilizante de concretos. Foram analisados nove traços diferentes, com relação água/cimento fixa $(0,45)$ e utilizando os cimentos CP II E-40, CP III-40, CP IV-40 e CP V-ARI. Quatro amostras com $0,8 \%$ de ARP, quatro sem o aditivo e uma contendo cimento CP III-40, ARP e fibra de polipropileno.

Moreira (2016) analisou, no estado fresco, o abatimento de tronco de cone e, no estado endurecido, resistência à compressão e à tração, módulo de elasticidade, penetração de água sob pressão, permeabilidade à água e absorção de água por capilaridade.

Moreira (2016) conclui que o aditivo redutor de permeabilidade é capaz de reduzir a permeabilidade dos concretos utilizados com os cimentos CP II E-40, CP III-40 e CP IV-40, em escalas diferentes. Entretanto, o $A R P$, inesperadamente, gerou um aumento da permeabilidade do concreto produzido com o cimento CP VARI. Por fim, constatou, por meio dos ensaios de penetração de água sob pressão e de absorção de água por capilaridade, que o traço que continha o ARP e a fibra sofreu um aumento na susceptibilidade à permeabilidade a água em relação ao traço sem a fibra.

$\mathrm{O}$ objetivo deste trabalho foi analisar o efeito de um aditivo cristalizante na autocicatrização de fissuras de até $0,4 \mathrm{~mm}$ em lajes de concreto armado, bem como avaliar a influência do aditivo cristalizante na resistência à compressão do concreto.

\section{Método}

O fluxograma mostrado na Figura 1 apresenta o programa experimental e as principais etapas (Figura 2).

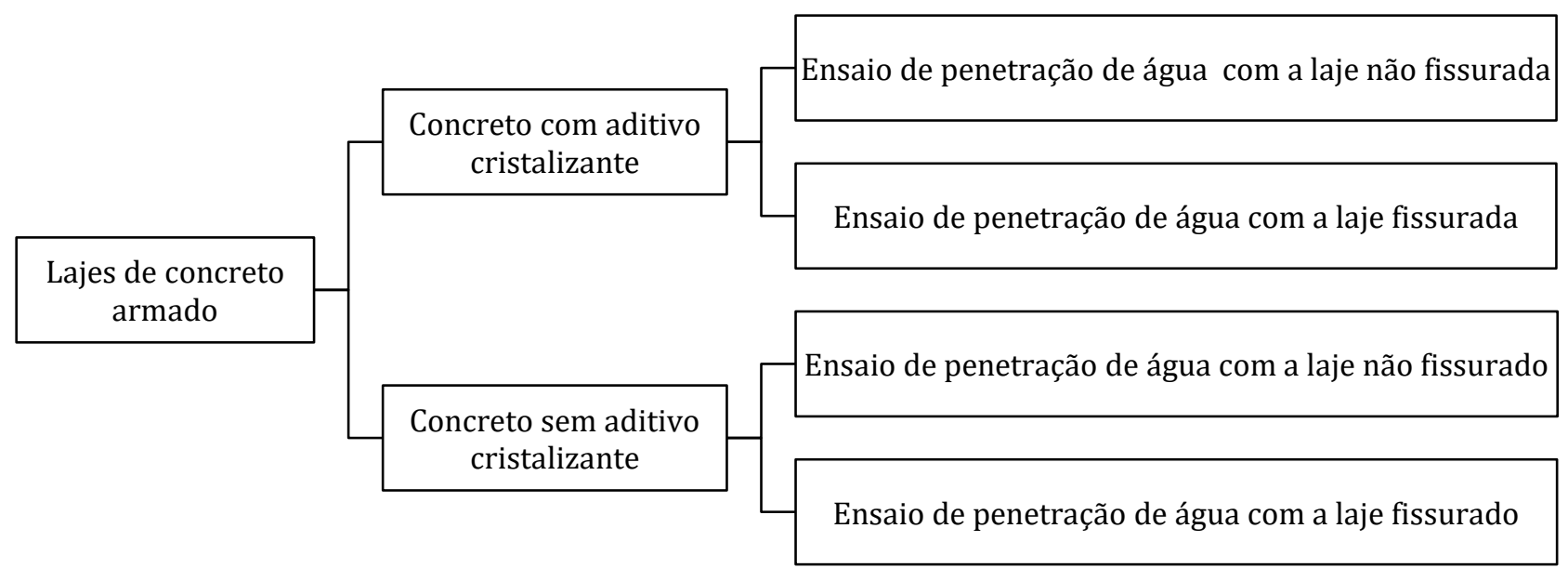

Figura 1 - Estudo realizado e principais ensaios realizados 


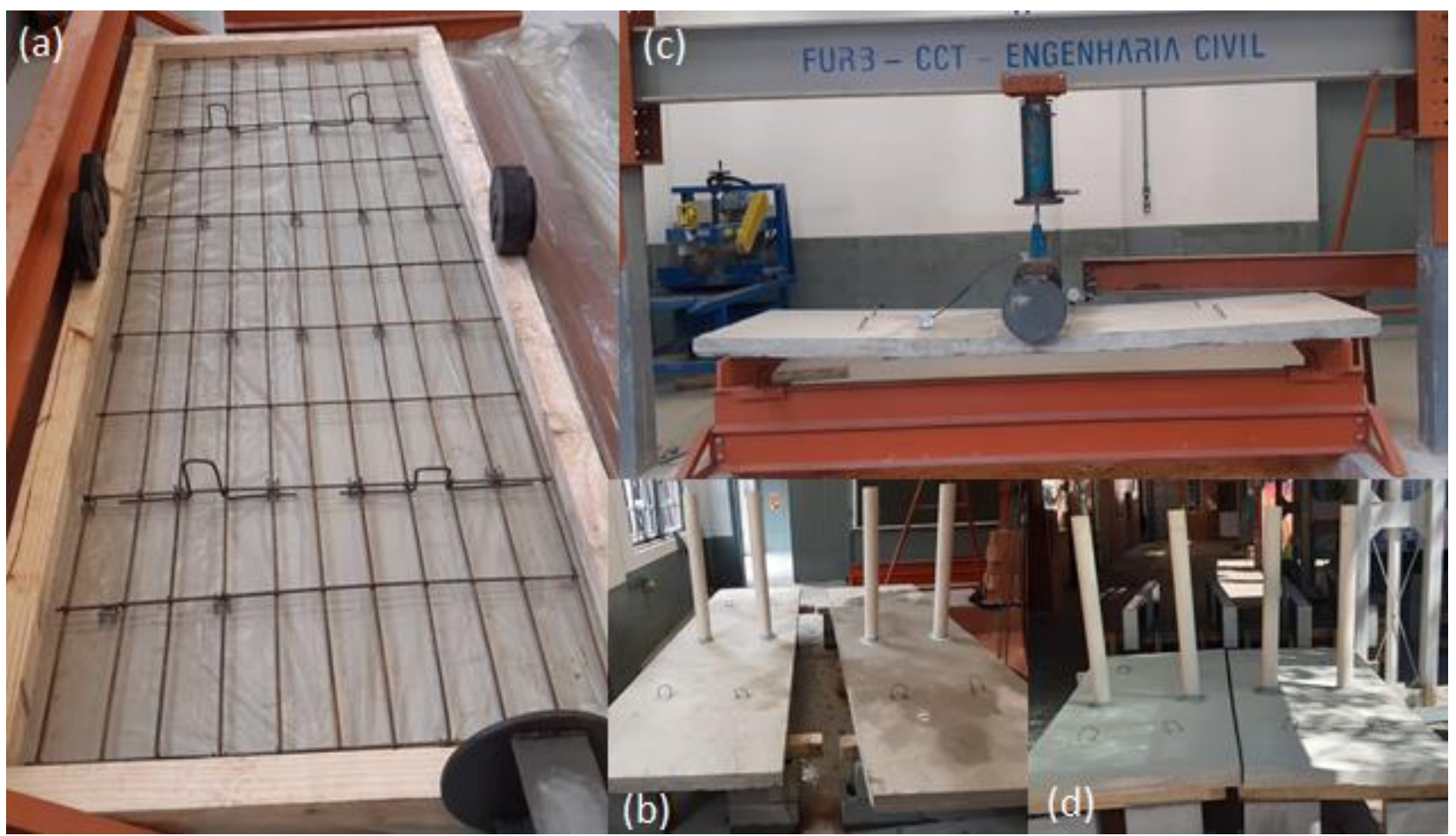

Figura 2 - Principais etapas de desenvolvimento do trabalho: (a) concretagem de 2 lajes; (b) desforma e realização de ensaio de estanqueidade com as lajes antes do carregamento (laje não fissurada); (c) carregamento das lajes com controle da abertura de fissura $(0,4 \mathrm{~mm})$; (d) realização de ensaio de etanqueidade com as lajes após o carregamento (laje fissurada); as setas indicam a sequencia cronológica das atividades

Foram concretadas duas lajes de concreto armado, do tipo maciça, com espessura igual a $8 \mathrm{~cm}$, definida conforme o item 13.2.4.1 da NBR 6118 (ABNT, 2014), adotou-se que as lajes seriam de piso, não em balanço. As lajes tinham $3 \mathrm{~m}$ de comprimento por $1 \mathrm{~m}$ de largura. Foram dimensionadas e detalhadas conforme a NBR 6118 (ABNT, 2014) e NBR 6120 (ABNT, 2019). A armadura utilizada foi $1 \varnothing 6,3 \mathrm{~mm}$ com espaçamento de 10,5 $\mathrm{cm}$ na longitudinal (comprimento da laje) e $1 \varnothing 6,3 \mathrm{~mm}$ com espaçamento de $33 \mathrm{~cm}$ na transversal (largura da laje). Foi adotado o cobrimento de 2,5 cm, determinado conforme a tabela 7.2 da NBR 6118 (ABNT, 2014). Para garantia do cobrimento das armaduras, foram utilizados espaçadores de plástico. Para o processo de adensamento do concreto, foi utilizado um vibrador de imersão, conforme as recomendações da NBR 14931 (ABNT, 2004). O concreto utilizado nas duas lajes tinham o mesmo traço sendo a única diferença a presença do aditivo cristalizandote. No Quadro 1 são apresentados os traço de concreto utlizados no trabalho.

Quadro 1 - Traços de concreto utilizados na pesquisa em $\mathrm{kg} / \mathrm{m}^{3}$

\begin{tabular}{|c|c|c|c|c|c|c|c|}
\hline Traço & $\begin{array}{c}\text { Cimento } \\
\left(\mathrm{kg} / \mathrm{m}^{3}\right)\end{array}$ & $\begin{array}{c}\text { Areia } \\
\left(\mathrm{kg} / \mathrm{m}^{3}\right)\end{array}$ & $\begin{array}{c}\text { Brita } \\
\left(\mathrm{kg} / \mathrm{m}^{3}\right)\end{array}$ & $\begin{array}{c}\text { Água } \\
\left(\mathrm{kg} / \mathrm{m}^{3}\right)\end{array}$ & $\begin{array}{c}\text { Aditivo } \\
\text { Cristalizante } \\
\left(\mathrm{kg} / \mathrm{m}^{3}\right)\end{array}$ & $\begin{array}{c}\text { Aditivo } \\
\text { superplastificante } \\
(\%)\end{array}$ & $\begin{array}{c}\text { Abatimento } \\
(\mathrm{mm})\end{array}$ \\
\hline Com cristalizante & 317 & 1015 & 897 & 138 & 2,53 & $0,80 \%$ & 100 \\
\hline Sem cristalizante & 317 & 1015 & 897 & 138 & - & $1,00 \%$ & 100 \\
\hline
\end{tabular}

Para a caracterização do concreto produzido foram moldados corpos de prova conforme as recomendações da NBR 5738 (ABNT, 2015b). Os corpos de prova utilizados são cilíndricos e com diâmetro e altura iguais a 10 e $20 \mathrm{~cm}$. Conforme determina o item 5.6.3.2 da NBR 12655 (ABNT, 2015a), foram moldados e rompidos 20 corpos de prova para cada traço, para fins de estabelecimento da resistência à compressão do concreto utilizado. Os ensaios foram realizados 28 dias após a concretagem de cada laje. Os ensaios de determinação da resistência à compressão seguiram as recomendações da NBR 5739 (ABNT, 2018).

Para analisar a influência do aditivo cristalizante incorporado ao concreto, no que tange à autocicatrização após surgimento de fissuras, foi adaptado o método de verificação de permeabilidade em telhas de concreto, da NBR 13858-2 (ABNT, 2009). No referido ensaio, é feita a verificação da permeabilidade através de pressão de coluna de água, onde pode ser evidenciado vazamento ou não, formação de gotas aderentes e aparecimento de manchas de umidade. A adaptação realizada neste trabalho consiste no emprego de uma 
coluna de água de $1.000 \mathrm{~mm}$ em substituição ao coluna de $250 \mathrm{~mm}$ empregada no método de referência. Os principais procedimentos realizados são assim descritos:

a. Após concretadas, as lajes permaneceram em laboratório, com temperatura entre 15 e $25^{\circ} \mathrm{C}$, recebendo cura úmida até atingirem a idade de 28 dias, para serem ensaiadas;

b. Em primeiro momento, foi realizada a desforma e o içamento das lajes, para fins de posicionamento no local de realização do ensaio. As lajes ficaram suspensas a uma altura suficiente para que se pudesse observar as suas faces inferiores.

c. Posteriormente, foi realizado o ensaio para análise da permeabilidade do concreto em situação não fissurada (apenas o peso próprio), que consistiu na fixação de tubos de PVC cilíndricos sobre as lajes (Figura 2-b).

d. Foram fixados, em cada laje, com uso de adesivo colante estrutural a base de epoxi, dois tubos de PVC com diâmetro igual a $100 \mathrm{~mm}$ que, após atingirem uma adesão considerável às lajes, foram preenchidos com uma altura de coluna d'água de $1.000 \mathrm{~mm}$ e, então, observados por 96 horas, com atenção para o nível d'água e o surgimento de manchas de umidade na base dos tubos e nas faces inferiores das lajes.

e. Após as 96 horas de observação, os tubos foram esvaziados e removidos e as lajes foram submetidas aos carregamentos centrados (Figura 2-e), para fins de formação de fissuras de até $0,4 \mathrm{~mm}$. Conforme os carregamentos eram aplicados, os valores de deformação da laje e abertura de fissuras foram obtidos, de modo a limitar a abertura das fissuras em $0,4 \mathrm{~mm}$. A relação entre as cargas aplicadas, deformações obtidas e aberturas de fissuras geradas nas lajes, com e sem aditivo cristalizante foram monitoradas e são apresentadas na Figura 3. Os carregamentos foram aplicados por um macaco hidráulico com capacidade de $3 \mathrm{tf}$ e as fissuras tiveram suas aberturas controladas por meio de um fissurômetro.

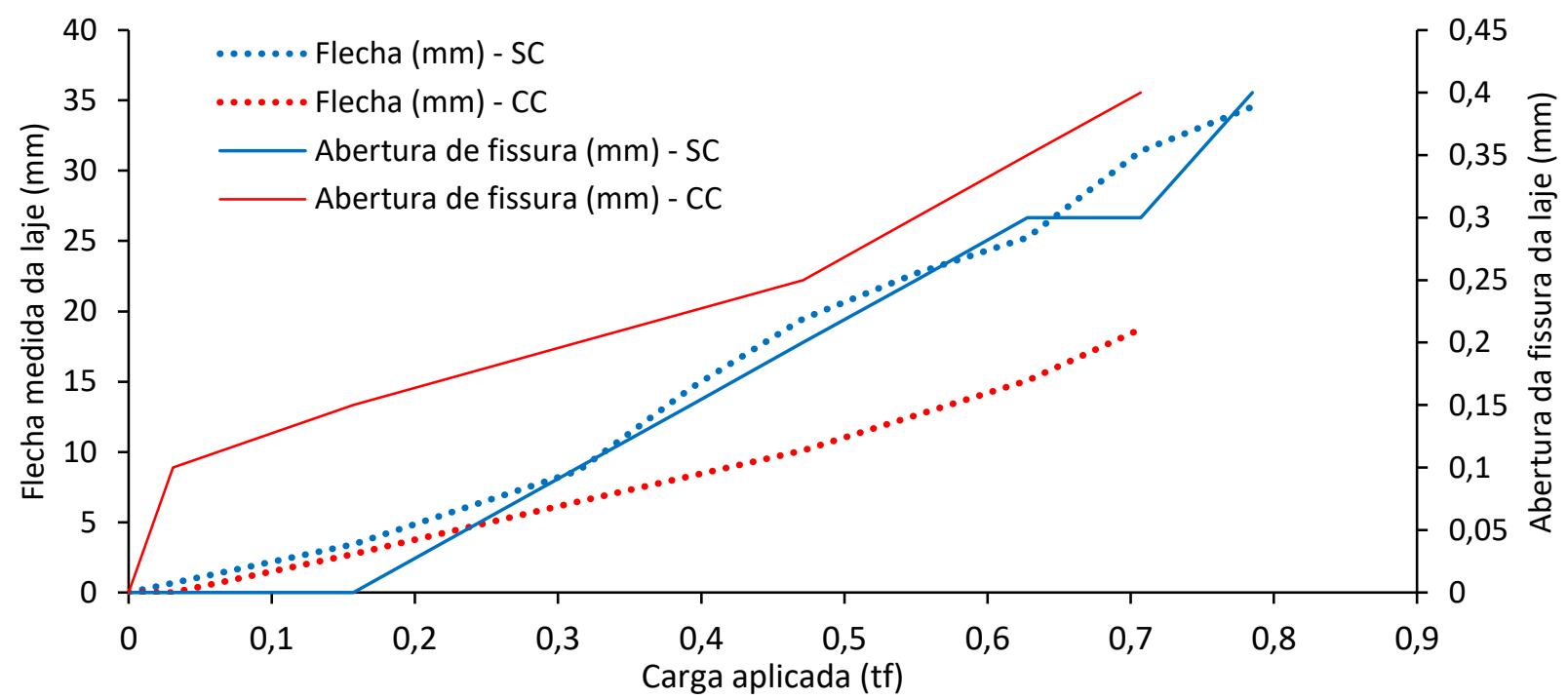

Figura 3 - Relação entre carga aplicada, deformação e abertura de fissura nas lajes com e sem aditivo cristalizante.

f. Após a obtenção de fissuras com abertura característica igual a 0,4 mm, em ambas as lajes, elas foram movidas do local, instaladas em ambiente coberto, e o sistema de tubos foi remontado, para que fosse iniciado o ensaio para a análise da permeabilidade do concreto em situação fissurada. As lajes foram monitoradas por 360 hoas o aparecimento de umidade nas bases dos tubos, além de gotejamento e manchas nas faces inferiores das lajes.

\section{Resultados}

\subsection{Ensaio de resistência à compressão do concreto}

Os corpos de prova moldados com o concreto utilizado na laje com e sem aditivo cristalizante foram ensaiados com idade igual a 28 dias. Na Figura 4, são apresentados os resultados individuais e médios do ensaio de resistência à compressão dos dois concreto. 


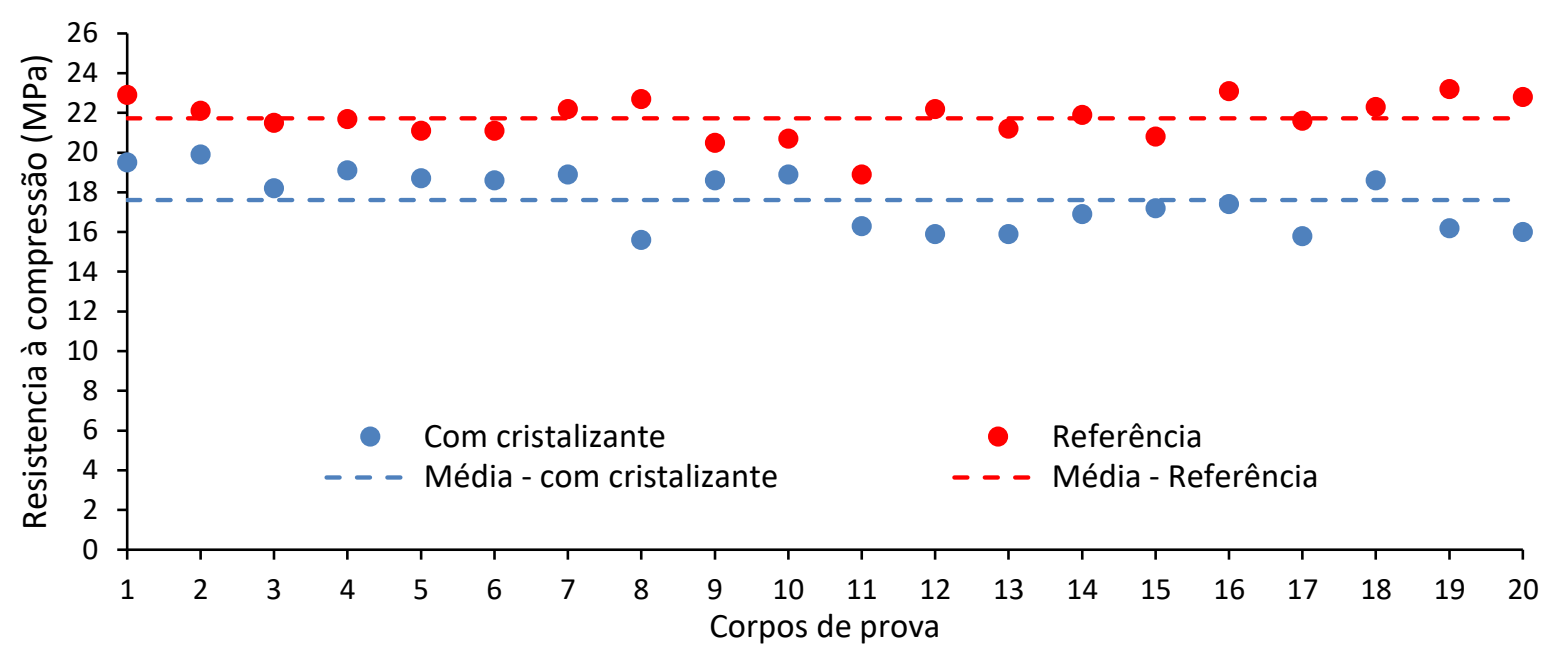

Figura 4 - Resistência à compressão dos corpos de prova de concretos com e sem aditivo cristalizante.

A resistência à compressão média e o desvio padrão do concreto com aditivo cristalizante foram iguais a 17,6 $\mathrm{MPa}$ e 1,4 MPa, respectivamente. A resistência à compressão média e o desvio padrão do concreto com aditivo cristalizante foram iguais a $21,7 \mathrm{MPa}$ e 1,1 MPa, respectivamente.

Os resultados obtidos nos ensaios de resistência à compressão do concreto mostraram que a incorporação do aditivo cristalizante ao traço do concreto, nas condições impostas, não levou à um aumento no valor da resistência à compressão do concreto, causando, pelo contrário, uma diminuição no valor da propriedade.

Moreira (2016) analisou a influência de um aditivo redutor de permeabilidade (ARP) sobre a resistência à compressão de concretos moldados com diversos traços, diversos tipos de cimento e com idades diferentes, e constatou que não houve variação significativa no valor das resistências médias dos corpos de prova analisados, independentemente do tipo do cimento utilizado ou da idade.

Por outro lado, Wiener (2019) estudou a influência de um aditivo cristalizante na resistência à compressão do concreto, aos 7 e 28 dias, utilizando cimento CP V ARI - RS, e constatou que aos 28 dias os corpos de prova com aditivo cristalizante apresentaram uma leve superioridade nos valores de resistência à compressão do concreto.

\subsection{Análise da permeabilidade da laje não fissurada}

No Quadro 2 são apresentados os resultados do ensaio para análise da permeabilidade da laje de concreto em situação não fissurada.

Quadro 2 - Variação do nível da água por tubo $(\mathrm{mm})$ para análise da permeabilidade do concreto em situação não fissurada

\begin{tabular}{|c|c|c|c|c|c|c|}
\hline \multirow{3}{*}{$\begin{array}{l}\text { Tempo } \\
\text { ensaio } \\
\text { (horas) }\end{array}$} & \multicolumn{3}{|c|}{ Laje com aditivo cristalizante } & \multicolumn{3}{|c|}{ Laje sem aditivo cristalizante } \\
\hline & \multicolumn{2}{|c|}{ Tubo } & \multirow{2}{*}{ Observação } & \multicolumn{2}{|c|}{ Tubo } & \multirow{2}{*}{ Observação } \\
\hline & 1 & 2 & & 1 & 2 & \\
\hline 24 & -5 & -6 & \multirow{2}{*}{$\begin{array}{l}\text { Não havia sinal de } \\
\text { umidade nas bases dos } \\
\text { tubos e na face inferior }\end{array}$} & 0 & 0 & \multirow{4}{*}{$\begin{array}{c}\text { Não há sinal de umidade nas } \\
\text { bases dos tubos e na face } \\
\text { inferior }\end{array}$} \\
\hline 48 & -6 & -10 & & 0 & -4 & \\
\hline 72 & -9 & -19 & \multirow{2}{*}{$\begin{array}{l}\text { Apresenta face inferior } \\
\text { seca e bases dos tubos } \\
\text { levemente úmidas }\end{array}$} & 0 & -8 & \\
\hline 96 & -19 & -20 & & 0 & -15 & \\
\hline
\end{tabular}

Ao final das 96 horas de observação, foi constatado que não havia umidade nas faces inferiores das lajes, nem tampouco manchas esbranquiçadas, comprovando que, apesar do rebaixamento do nível da água nos tubos, não houve percolações consideráveis de água pelo interior do elemento de concreto armado. No entanto, constatou-se que houve absorção de água por parte do concreto na laje com aditivo cristalizante, fato evidenciado pelas manchas de umidade surgidas ao redor do adesivo estrutural em suas bases, situação 
que é mostrada na Figura 5-a e 5-b. Contudo, na laje de referência (sem aditivo cristalizante) não foram constatadas manchas de umidade como pode ser visto na Figura 5-c e 5-d.

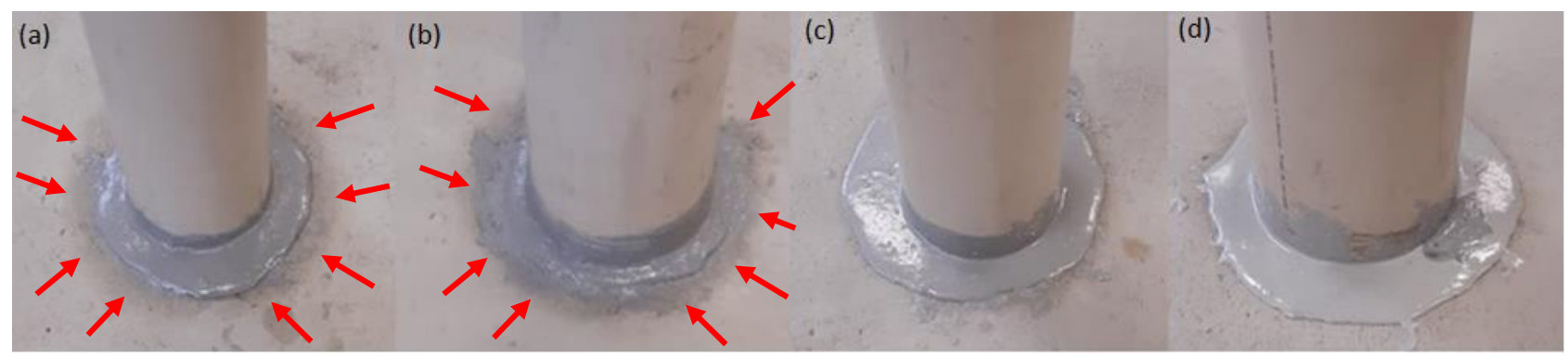

Figura 5 - Base dos tubos no ensaio de estanqueidade da laje não fissurada (a) e (b) com cristalizante; (c) e (d) sem cristalizante após 96 horas de ensaio.

\subsection{Análise da permeabilidade da laje fissurada}

No Quadro 3 são apresentados os resultados do ensaio para análise da permeabilidade da laje de concreto em situação fissurada.

Quadro 3 - Variação do nível da água por tubo $(\mathrm{mm})$ para análise da permeabilidade do concreto em situação fissurada

\begin{tabular}{|c|c|c|c|c|c|c|}
\hline \multirow{3}{*}{$\begin{array}{l}\text { Tempo } \\
\text { ensaio } \\
\text { (horas) }\end{array}$} & \multicolumn{3}{|r|}{ Laje com aditivo cristalizante } & \multicolumn{3}{|c|}{ Laje sem aditivo cristalizante } \\
\hline & \multicolumn{2}{|c|}{ Tubo } & \multirow{2}{*}{ Observação } & \multicolumn{2}{|c|}{ Tubo } & \multirow{2}{*}{ Observação } \\
\hline & 1 & 2 & & 1 & 2 & \\
\hline 24 & -5 & -15 & $\begin{array}{l}\text { Não há sinal de umidade nas bases dos tubos } \\
\text { e na face inferior }\end{array}$ & -5 & -6 & \multirow{13}{*}{$\begin{array}{l}\text { Não há sinal de umidade } \\
\text { nas bases dos tubos e na } \\
\text { face inferior }\end{array}$} \\
\hline 48 & -11 & -19 & \multirow{4}{*}{$\begin{array}{l}\text { Apresenta face inferior seca e bases dos } \\
\text { tubos levemente úmidas }\end{array}$} & -9 & -9 & \\
\hline 96 & -24 & -30 & & -16 & -20 & \\
\hline 120 & -27 & -39 & & -17 & -20 & \\
\hline 144 & -27 & -39 & & -20 & -20 & \\
\hline 168 & -31 & -45 & \multirow{4}{*}{$\begin{array}{c}\text { Não há sinal de umidade nas bases dos tubos } \\
\text { e na face inferior }\end{array}$} & -23 & -22 & \\
\hline 192 & -36 & -50 & & -24 & -27 & \\
\hline 216 & -37 & -52 & & -25 & -27 & \\
\hline 264 & -52 & -67 & & -39 & -40 & \\
\hline 288 & -57 & -73 & \multirow{4}{*}{$\begin{array}{c}\text { Não há sinal de umidade nas bases dos tubos } \\
\text { e na face inferior. Aparecimento de manchas } \\
\text { esbranquiçadas ao longo das fissuras }\end{array}$} & -39 & -40 & \\
\hline 312 & -64 & -78 & & -42 & -45 & \\
\hline 336 & -64 & -84 & & -44 & -46 & \\
\hline 360 & -67 & -85 & & -47 & -49 & \\
\hline
\end{tabular}

Os dados evidenciam o rebaixamento do nível d'água nos tubos de PVC por tempo de ensaio e a situação constatada visualmente quanto ao aparecimento de manchas de umidade na base dos tubos e nas faces inferiores das lajes, além do surgimento de manchas esbranquiçadas ao longo das fissuras. Conforme os resultados expostos, contatou-se que o rebaixamento do nível d'água nos tubos de PVC instalados na laje com aditivo cristalizante foi muito superior ao encontrado na laje sem aditivo cristalizante, havendo uma diferença relevante nos dados entre os tubos da mesma laje.

Pôde-se evidenciar, conforme a Figura 6-a, que houve uma absorção de água nas bases dos tubos da laje com aditivo cristalizante, a qual foi visualizada levemente no segundo dia de ensaio e pode ser vista com clareza no quinto dia. A base dos tubos da laje sem aditivo cristalizante, pelo contrário, não apresentou umidade em momento algum do ensaio.

A formação de manchas de umidade e de gotejamento nas faces inferiores das lajes não constatada em momento algum do experimento. Entretanto, a partir do décimo segundo dia de ensaio, pode ser observada a formação de manchas esbranquiçadas no entorno das fissuras da laje com aditivo cristalizante, conforme é mostrado na Figura 6-b, o que indica que houve lixiviação de hidróxido de cálcio (um dos resultados da hidratação do cimento), evidenciando passagem da d'água atráves das fissuras da laje. 


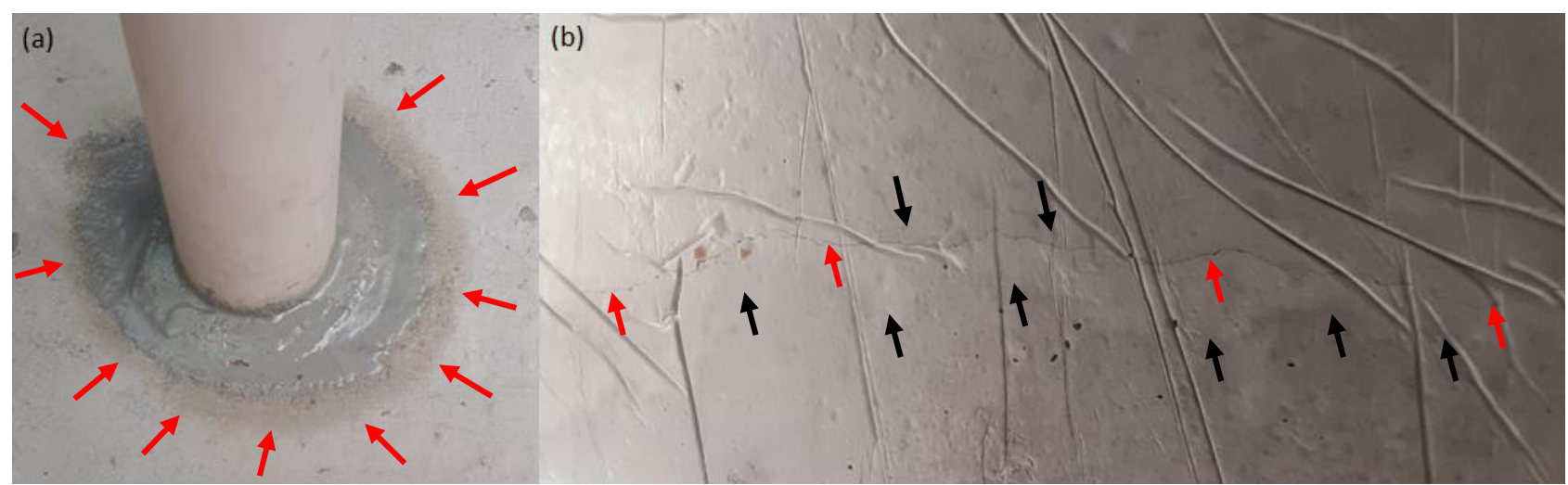

Figura 6 - Base dos tubos no ensaio de estanqueidade da laje não fissurada as 144 horas de ensaio (a); e mancha esbranquiçada (setas pretas) ao longo de fissura (setas vermelhas) ocasionada pela lixiviação de hidróxido de cálcio

A ocorrencia se manteve na laje com aditivo cristalizante até o fim do experimento, se tornando mais evidente ao longo do tempo (Figura 7). De forma contrária, a face inferior da laje sem aditivo cristalizante se manteve livre tanto de manchas umidade, como de manchas esbranquiçadas ao longo das fissuras.

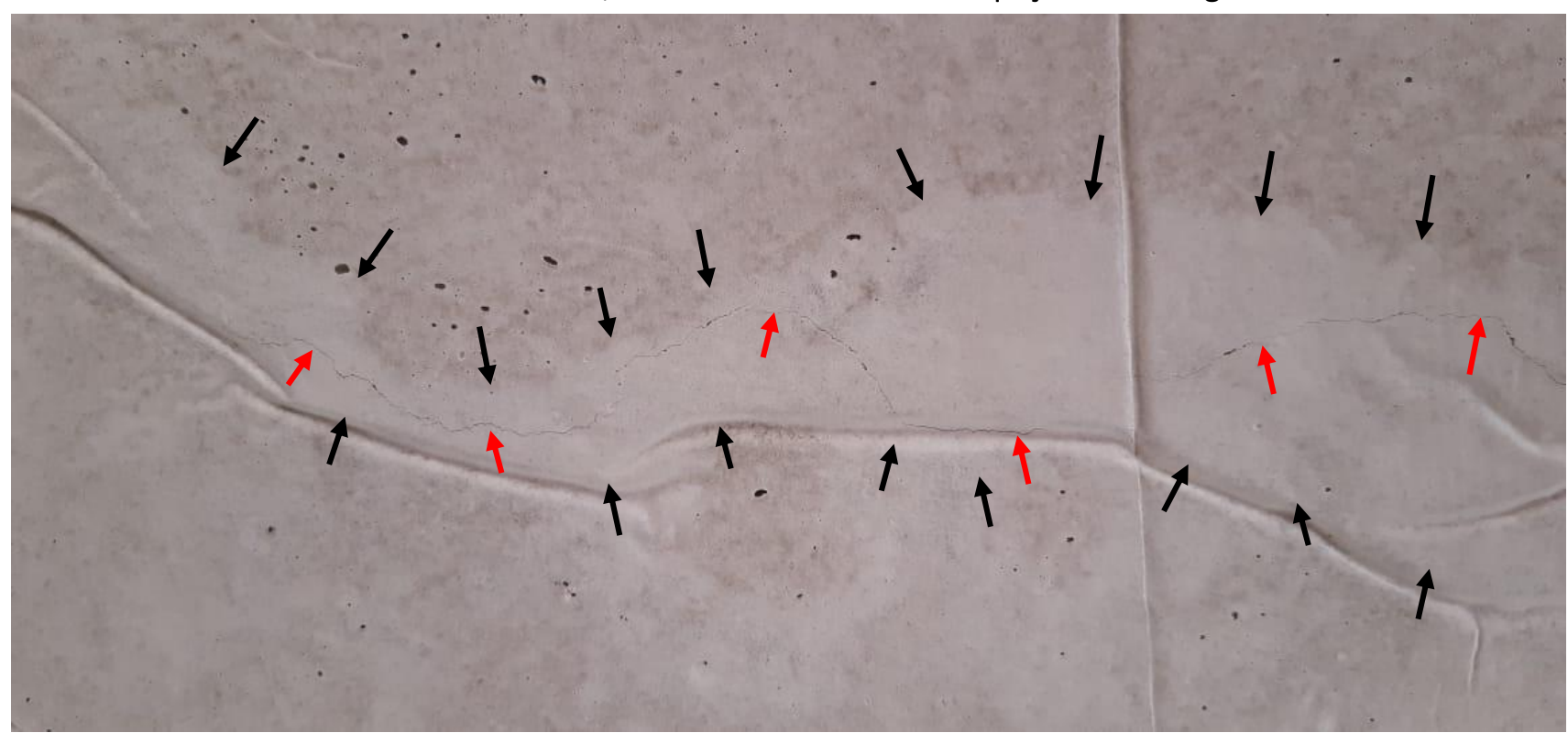

Figura 7 - Mancha esbranquiçada (setas pretas) ao longo de fissura (setas vermelhas) ocasionada pela lixiviação de hidróxido de cálcio.

Wiener (2019) também analisou a influência do aditivo cristalizante na autocicatrização do concreto. De forma semelhante ao que foi executado neste trabalho, o autor moldou corpos de prova de dimensões $30 \mathrm{x}$ $100 \times 7 \mathrm{~cm}$ e os submeteu aos ensaios de penetração de água sob pressão em situação fissurada e não fissurada.

Após observar as lajes por 14 dias, Wiener (2019) concluiu que o aditivo cristalizante reduziu a permeabilidade do concreto, fato que foi evidenciado pela diminuição das manchas de umidade geradas na face inferior da laje. A percolação da água através do corpo de prova em formato de placa foi confirmada pelo aparecimento de manchas esbranquiçadas ao longo da fissura, as quais são originadas pela lixiviação do hidróxido de cálcio, um dos resultados da hidratação do concreto.

Quando comparados com os resultados por Wiener (2019), os resultados obtidos neste trabalho são mais conservadores quanto à afirmação de que o aditivo cristalizante realmente é capaz de selar as fissuras do concreto de até $0,4 \mathrm{~mm}$. Isso porque não foi constatada nenhuma evidência de uma diminuição da percolação da água na laje com aditivo cristalizante, pelo contrário, foi no elemento estrutural com o aditivo em que a passagem de água foi evidenciada. 


\section{Conclusões}

Este trabalho teve por finalidade a análise do efeito de um aditivo cristalizante na autocicatrização das fissuras do concreto de até $0,4 \mathrm{~mm}$. Além disso, buscou-se avaliar a influência do aditivo cristalizante na resistência à compressão do concreto.

Pôde-se concluir que a incorporação do aditivo cristalizante ao concreto não gerou um aumento relevante na resistência à compressão do elemento estrutural, pelo contrário, gerou uma redução, que, quando comparada à trabalhos com temas e objetivos semelhantes, diferenciando-se outros autores obtiveram valores de resistência média e característica mais próximos entre si para concretos com e sem aditivo cristalizante.

Quanto ao fenômeno da autocicatrização, pouco pôde-se concluir. O surgimento de manchas esbranquiçadas na laje com aditivo cristalizante mostra que houve a percolação de água através do elemento estrutural. Porém, a ausência desta atividade na laje sem aditivo cristalizante não nos permite avaliar a capacidade selante do aditivo.

O que é possível afirmar a cerca dos resultados obtidos no ensaio de penetração de água sob pressão é que respeitando o valor máximo de abertura característica de fissuras, igual a 0,4 mm, definido pela NBR 6118 (ABNT, 2014), a quantidade de água percolada em ambas as lajes não foi suficiente para um gotejamento, que, em uma situação real, poderia ocasionar em danos para uma edificação.

\section{Referências Bibliográficas}

Associação brasileira de normas técnicas. NBR 13858-2: Telhas de concreto Parte 2: Requisitos e métodos de ensaio. Rio de Janeiro: ABNT, 2009b. 32 p.

Associação brasileira de normas técnicas. NBR 14931: Execução de estruturas de concreto - Procedimento. Rio de Janeiro: ABNT, 2004. 53 p.

Associação brasileira de normas técnicas. NBR 5738: Concreto - Procedimento para moldagem e cura de corpos de prova. Rio de Janeiro: ABNT, 2015b. 9 p.

Associação brasileira de normas técnicas. NBR 5739: Concreto - Ensaio de compressão de corpos de prova cilíndricos. Rio de Janeiro: ABNT, 2018. 9 p.

Associação brasileira de normas técnicas. NBR 6118: projeto de estruturas de concreto - procedimento. Rio de Janeiro: ABNT, 2014. 238 p.

Associação brasileira de normas técnicas. NBR 6120: Ações para o cálculo de estruturas de edificações. Rio de Janeiro: ABNT, 2019. 60 p.

Bianchin, Felipe Hirata. Avaliação da autocicatrização em concretos produzidos com aditivo cristalizante e fissurados nas primeiras idade. 2018. 102 f. TCC (Graduação) - Curso de Engenharia Civil, Universidade Federal do Rio Grande do Sul, Porto Alegre, 2018. Disponível em: <https://www.lume.ufrgs.br/handle/10183/188442> Acesso em: 20 maio 2020.

Moreira, Mirellen Mara. Efeito do aditivo redutor de permeabilidade em concretos com diferentes tipos de cimento portland - contribuição aos processos de autocicatrização. 2016. 162 f. Dissertação (Mestrado) Curso de Engenharia Civil, Departamento de Engenharia Civil e Ambiental, Universidade de Brasília, Brasília, 2016. Disponível em: < https://repositorio.unb.br/handle/10482/22278> Acesso em: 21 maio 2020.

Takagi, Emílio Minoru. Concretos autocicatrizantes com cimentos brasileiros de escória de alto-forno ativados por catalisador cristalino. 2013. 130 f. Dissertação de mestrado em Engenharia de Infraestrutura Aeroportuária - Instituto Tecnológico de Aeronáutica, São José dos Campos, 2013. Disponível em: < http://www.bdita.bibl.ita.br/>. Acesso em: 20 maio 2020.

Wiener, Leonardo Antônio Hardtke. Autocicatrização do concreto e os efeitos da adição de aditivos cristalizantes em sua composição. 2019. 11 f. TCC (Graduação) - Curso de Engenharia Civil, Pontífica Universidade Católica do Rio Grande do Sul (PUCRS), Porto Alegre, 2019. 